\title{
Prognostic significance of the albumin-to- globulin ratio for upper tract urothelial carcinoma
}

\author{
Shota Omura', Satoru Taguchi ${ }^{1 *}$ D, Shogo Miyagawa', Ryuki Matsumoto ${ }^{1}$, Mio Samejima', Naoki Ninomiya', \\ Kazuki Masuda', Yu Nakamura', Tsuyoshi Yamaguchi', Manami Kinjo ', Mitsuhiro Tambo', Takatsugu Okegawa', \\ Eiji Higashihara² and Hiroshi Fukuhara'
}

\begin{abstract}
Background: Although the albumin-to-globulin ratio (AGR) is a promising biomarker for various malignancies, few studies have investigated its prognostic significance for upper tract urothelial carcinoma (UTUC).

Methods: This retrospective study conformed to the REporting recommendations for tumour MARKer prognostic studies (REMARK) guideline. We reviewed 179 patients with UTUC who underwent radical nephroureterectomy at our institution between 2008 and 2018. Associations of preoperative clinicopathological factors, including the AGR, with cancer-specific survival (CSS) and overall survival (OS) were assessed. The Cox proportional hazards model was used for univariate and multivariable analyses. AGR was dichotomized as $<1.25$ and $\geq 1.25$, according to the most discriminatory cutoff determined from the receiver operating characteristic curve analysis.

Results: During a median follow-up of 34 months after surgery, 37 patients died from UTUC and 13 died of other causes. The preoperative AGR significantly correlated with pathological T stage, pathological N stage, and adjuvant chemotherapy. Multivariate analyses demonstrated that a decreased $(<1.25)$ preoperative AGR was an independent poor prognostic factor for both CSS (hazard ratio $[H R]=2.81, P<0.01)$ and OS $(H R=2.09, P<0.05)$.
\end{abstract}

Conclusions: Preoperative AGR $<1.25$ might serve as a useful prognostic marker for patients with UTUC undergoing radical nephroureterectomy.

Keywords: AGR, Albumin-to-globulin ratio, Biomarker, Radical nephroureterectomy, REMARK, Upper tract urothelial carcinoma

\section{Background}

Upper tract urothelial carcinoma (UTUC) is a relatively rare malignancy that accounts for $5-10 \%$ of urothelial carcinomas and generally has a poor prognosis $[1,2]$. Radical nephroureterectomy with bladder cuff excision is the gold standard treatment for nonmetastatic UTUC

\footnotetext{
*Correspondence: satorutaguchi33@gmail.com

'Department of Urology, Kyorin University School of Medicine, 6-20-2 Shinkawa, Mitaka, Tokyo 181-8611, Japan

Full list of author information is available at the end of the article
}

[3], whereas up to $19 \%$ of patients with UTUC have metastasis upon initial presentation [4].

Clinicopathological factors [5-15] including laboratory markers [11-15] serve as prognostic markers for UTUC. In contrast, the significance of the albumin-to-globulin ratio (AGR), which serves as a useful biomarker for various malignancies [16-26], has not been fully investigated in UTUC [23-26]. Therefore, the present study assessed the significance of the association of preoperative AGR on oncological outcomes of patients with UTUC undergoing radical nephroureterectomy. 


\section{Methods}

This retrospective study conformed to the REporting recommendations for tumour MARKer prognostic studies (REMARK) guideline [27] (Supplementary Table 1 shows the REMARK checklist of the present study). This study was approved by the internal institutional review board of Kyorin University School of Medicine (approval number: 1154).

\section{Patients}

We retrospectively reviewed 185 consecutive patients who underwent radical nephroureterectomy with curative intent at Kyorin University Hospital between 2008 and 2018. We excluded six patients because of pathological diagnoses of urothelial dysplasia $(n=3)$, renal cell carcinoma $(n=2)$, and squamous cell carcinoma $(n=1)$, which left 179 available for analysis.

\section{Preoperative AGR}

Routine preoperative blood tests including serum total protein and albumin levels $(\mathrm{g} / \mathrm{dl})$ were performed within 1 month before surgery. The AGR was calculated using the following formula: AGR = [albumin / (total protein albumin)]. No patient had active infectious disorders during the blood tests.

\section{Endpoints and follow-up}

We assessed the associations of preoperative clinicopathological factors, including the AGR, with cancer-specific survival (CSS) and overall survival (OS). The follow-up period started on the day of surgery. Follow-up information was obtained as of October 2018.

\section{Statistical analysis}

Receiver operating characteristic (ROC) curve analysis was used to determine the optimal cutoff value of the AGR. Sensitivity, specificity and area under the curve (AUC) were calculated using a $2 \times 2$ contingency table for different cutoff values of the AGR. The optimal cutoff value of the AGR was determined by maximization of the Youden's index [Sensitivity - $(1-$ Specificity $)]$. Relations of the AGR to other variables were evaluated using the $X^{2}$ test or Spearman's rank correlation coefficient. Survival curves were generated using the KaplanMeier method and compared using log-rank tests. The Cox proportional hazard regression model was used for univariate and multivariate analyses. All statistical analyses were performed using JMP Pro version 14.0.0 (SAS Institute, Cary, NC, USA). $P<0.05$ was considered to indicate a significant difference.

\section{Results}

Patients' baseline characteristics are summarized in Table 1. The median follow-up was 34 months (interquartile
Table 1 Patient characteristics $(n=179)$

\begin{tabular}{|c|c|}
\hline Parameter & Value \\
\hline Age at surgery, years, median (IQR) & $75(66-79)$ \\
\hline \multicolumn{2}{|l|}{ Sex, no. (\%): } \\
\hline Male & $132(73.7)$ \\
\hline Female & $47(26.3)$ \\
\hline \multicolumn{2}{|l|}{ Surgical technique, no. (\%): } \\
\hline Open & $16(8.9)$ \\
\hline Laparoscopic & $163(91.1)$ \\
\hline \multicolumn{2}{|l|}{ Tumor location, no. (\%): } \\
\hline Renal pelvis & $96(53.6)$ \\
\hline Ureter & $81(45.3)$ \\
\hline Both & $2(1.1)$ \\
\hline \multicolumn{2}{|l|}{ Tumor grade, no. (\%): } \\
\hline G1 & $10(5.6)$ \\
\hline G2 & $94(52.5)$ \\
\hline G3 & $75(41.9)$ \\
\hline \multicolumn{2}{|l|}{ Pathological T stage, no. (\%): } \\
\hline $\mathrm{Ta} / 1 /$ is & $91(50.8)$ \\
\hline $\mathrm{T} 2$ & $13(7.3)$ \\
\hline T3 & $70(39.1)$ \\
\hline $\mathrm{T} 4$ & $5(2.8)$ \\
\hline \multicolumn{2}{|l|}{ Pathological N stage, no. (\%): } \\
\hline $\mathrm{NO} / \mathrm{x}$ & $157(87.7)$ \\
\hline N1 & $16(8.9)$ \\
\hline $\mathrm{N} 2$ & $6(3.4)$ \\
\hline N3 & $0(0)$ \\
\hline \multicolumn{2}{|l|}{ Adjuvant chemotherapy, no. (\%): } \\
\hline Yes & $39(21.8)$ \\
\hline No & $140(78.2)$ \\
\hline \multicolumn{2}{|l|}{ Bladder cancer status, no. (\%): } \\
\hline No & $145(81.0)$ \\
\hline Previous & 19 (10.6) \\
\hline Synchronous & $15(8.4)$ \\
\hline AGR, median (IQR) & $1.41(1.18-1.63)$ \\
\hline Follow-up duration, months, median (IQR) & $35(17-63)$ \\
\hline
\end{tabular}

Abbreviations: $A G R$ albumin-to-globulin ratio, $I Q R$ interquartile range

range [IQR], 17-63) months. Thirty-seven patients died from UTUC and 13 died of other causes. ROC curve analysis identified 1.25 as the most discriminatory cutoff value of AGR by maximization of the Youden's index [Sensitivity - $(1-$ Specificity $)$ ] for both endpoints of CSS and OS (Fig. 1).

$X^{2}$ test revealed pathological $\mathrm{T}$ stage $(\geq \mathrm{T} 3, P<0.01)$, pathological $\mathrm{N}$ stage $(\mathrm{N} 1-3, P<0.01)$, and adjuvant chemotherapy (yes, $P<0.05$ ) to be significantly associated with $\mathrm{AGR}<1.25$, while the other variables (sex, 


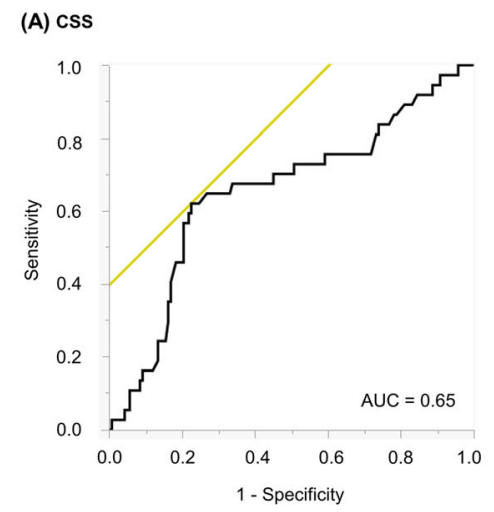

\begin{tabular}{|l|l|l|l|l|}
\hline $\begin{array}{l}\text { Cutoffs } \\
\text { of AGR }\end{array}$ & Sensitivity & Specificity & $\begin{array}{l}\text { Sensitivity - } \\
(1-\text { Specificity) }\end{array}$ & AUC \\
\hline$<1.10$ & $30 \%$ & $84 \%$ & $14 \%$ & 0.57 \\
\hline$<1.15$ & $41 \%$ & $83 \%$ & $24 \%$ & 0.62 \\
\hline$<1.20$ & $46 \%$ & $80 \%$ & $26 \%$ & 0.63 \\
\hline$<1.25$ & $62 \%$ & $78 \%$ & $40 \%$ (maximized) & 0.70 \\
\hline$<1.30$ & $65 \%$ & $70 \%$ & $35 \%$ & 0.67 \\
\hline$<1.35$ & $68 \%$ & $63 \%$ & $31 \%$ & 0.65 \\
\hline$<1.40$ & $68 \%$ & $55 \%$ & $23 \%$ & 0.61 \\
\hline$<1.45$ & $70 \%$ & $51 \%$ & $21 \%$ & 0.60 \\
\hline$<1.50$ & $73 \%$ & $46 \%$ & $19 \%$ & 0.59 \\
\hline$<1.55$ & $76 \%$ & $38 \%$ & $14 \%$ & 0.57 \\
\hline$<1.60$ & $76 \%$ & $30 \%$ & $6 \%$ & 0.53 \\
\hline
\end{tabular}

(B) os

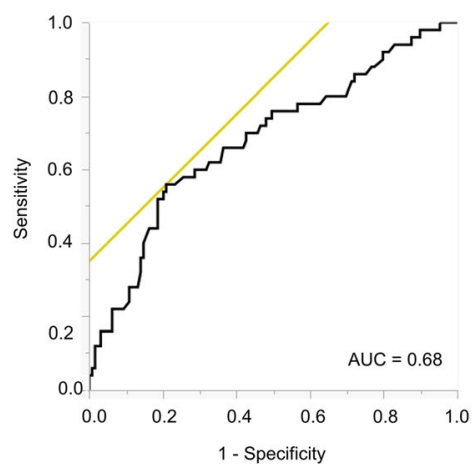

\begin{tabular}{|l|l|l|l|l|}
\hline $\begin{array}{l}\text { Cutoffs } \\
\text { of AGR }\end{array}$ & Sensitivity & Specificity & $\begin{array}{l}\text { Sensitivity - } \\
(1-\text { Specificity) }\end{array}$ & AUC \\
\hline$<1.10$ & $32 \%$ & $86 \%$ & $18 \%$ & 0.59 \\
\hline$<1.15$ & $40 \%$ & $85 \%$ & $25 \%$ & 0.63 \\
\hline$<1.20$ & $44 \%$ & $81 \%$ & $25 \%$ & 0.63 \\
\hline$<1.25$ & $\mathbf{5 6} \%$ & $79 \%$ & $35 \%$ (maximized) & 0.68 \\
\hline$<1.30$ & $60 \%$ & $71 \%$ & $31 \%$ & 0.66 \\
\hline$<1.35$ & $62 \%$ & $64 \%$ & $26 \%$ & 0.63 \\
\hline$<1.40$ & $68 \%$ & $57 \%$ & $25 \%$ & 0.63 \\
\hline$<1.45$ & $72 \%$ & $53 \%$ & $25 \%$ & 0.63 \\
\hline$<1.50$ & $76 \%$ & $49 \%$ & $25 \%$ & 0.62 \\
\hline$<1.55$ & $78 \%$ & $40 \%$ & $18 \%$ & 0.59 \\
\hline$<1.60$ & $80 \%$ & $32 \%$ & $12 \%$ & 0.56 \\
\hline
\end{tabular}

Fig. 1 ROC curve analyses for (a) CSS and (b) OS. The optimal cutoff value of AGR was estimated as $<1.25$ by maximizing the Youden's index [Sensitivity - (1 - Specificity)] for both endpoints of CSS and OS. Abbreviations: AGR = albumin-to-globulin ratio; CSS = cancer-specific survival; $\mathrm{OS}=$ overall survival; $\mathrm{ROC}=$ receiver operating characteristic

surgical technique, tumor location, tumor grade and previous or synchronous bladder cancer) were not. Spearman's rank correlation coefficient showed a weakly significant negative correlation between age at surgery and the AGR $(\rho=-0.25, P<0.01)$.

Kaplan-Meier curves with log-rank tests showed significant associations of preoperative AGR $<1.25$ with shorter CSS (Fig. 2) and OS (Fig. 3). Multivariate Cox proportional hazard regression analyses identified preoperative AGR $<1.25$ as an independent poor prognostic factor for both CSS (hazard ratio $[\mathrm{HR}]=2.81, P<0.01$ ) (Table 2) and OS $(\mathrm{HR}=2.09, P<0.05$; Table 3$)$.

\section{Discussion}

The present study demonstrates that a decreased $(<1.25)$ preoperative AGR was an independent indicator of poor prognosis for CSS and OS of patients with UTUC treated with radical nephroureterectomy.

Clinicopathological factors that serve as prognostic factors for UTUC [5-15] include sex [5], age [6], tumor size $[7,8]$, ureteral involvement [9], and body mass index [10], as well as laboratory markers [11-15] such as the neutrophil-to-lymphocyte ratio [11, 12], albumin [13], hemoglobin [14], and the prognostic nutritional index [15]. On the other hand, the AGR has been reported as a useful biomarker in various malignancies [16-26], including urological cancers [20-26]. However, the significance of the AGR as a prognostic marker for UTUC has not been fully investigated [23-26]. For example, a study of a Chinese cohort of 187 operable patients with UTUC [23] demonstrated that AGR $<1.45$ is an independent risk factor for poorer CSS and OS. Another study of a Chinese cohort of 620 patients with UTUC treated with radical nephroureterectomy found that AGR $<1.45$ is an independent predictor of adverse pathologic features, recurrence-free survival, CSS, and OS [24]. Similarly, analysis of a Japanese cohort of 124 patients with UTUC undergoing radical nephroureterectomy identified AGR $<1.40$ as an independent prognostic factor for recurrence-free survival, CSS, and OS [25]. Finally, another Japanese study comprising 105 patients with UTUC undergoing radical nephroureterectomy reported that AGR $<1.24$ was an independent predictor for both worse disease-free and overall survivals [26]. Our results are consistent with those of these previous reports and add further evidence in this field.

The association between a low AGR and poor outcome of patients with cancer requires further research. However, the available data show that poor nutritional status or hypoalbuminemia is a negative prognostic factor for certain malignancies $[13,15,16]$. Chronic inflammation involving serum globulins plays a crucial 


\section{css}

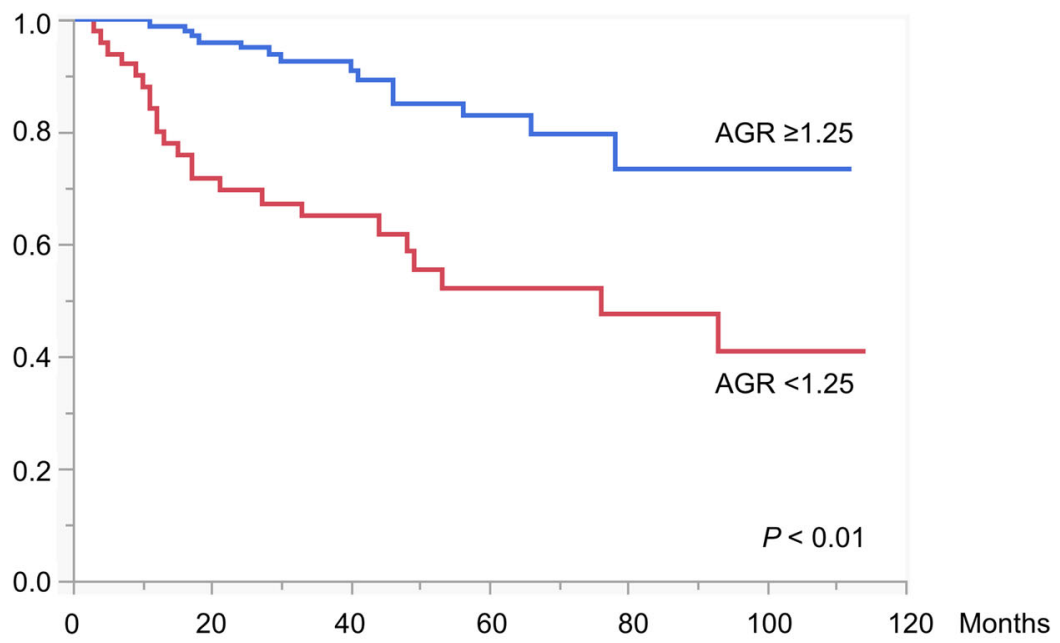

Number at risk:

$\begin{array}{lrrrrrrr}\text { AGR }<1.25 & 55 & 34 & 24 & 15 & 10 & 3 & 0 \\ \text { AGR } \geq 1.25 & 124 & 92 & 58 & 31 & 11 & 4 & 0\end{array}$

Fig. 2 Kaplan-Meier curves depicting CSS in patients with $A G R<1.25$ versus $\geq 1.25(P<0.01$, log-rank test). Abbreviations: $A G R=$ albumin-toglobulin ratio; CSS = cancer-specific survival

role in tumor proliferation, immune evasion, and metastasis. These serum globulins secreted by tumor-related cells reportedly promote tumor development, immunosuppression, and metastasis [16]. A low AGR may thus reflect the degree of poor nutritional status (hypoalbuminemia) and tumor progression (hyperglobulinemia) in a more sensitive manner than either measure alone and may therefore serve as a highly significant prognostic biomarker. Based on a similar concept as AGR (i.e. use of a ratio), several systemic inflammatory markers, such as the neutrophil-to-lymphocyte ratio [11, 12, 28], platelet-to-lymphocyte ratio [28], and lymphocyte-to-

OS

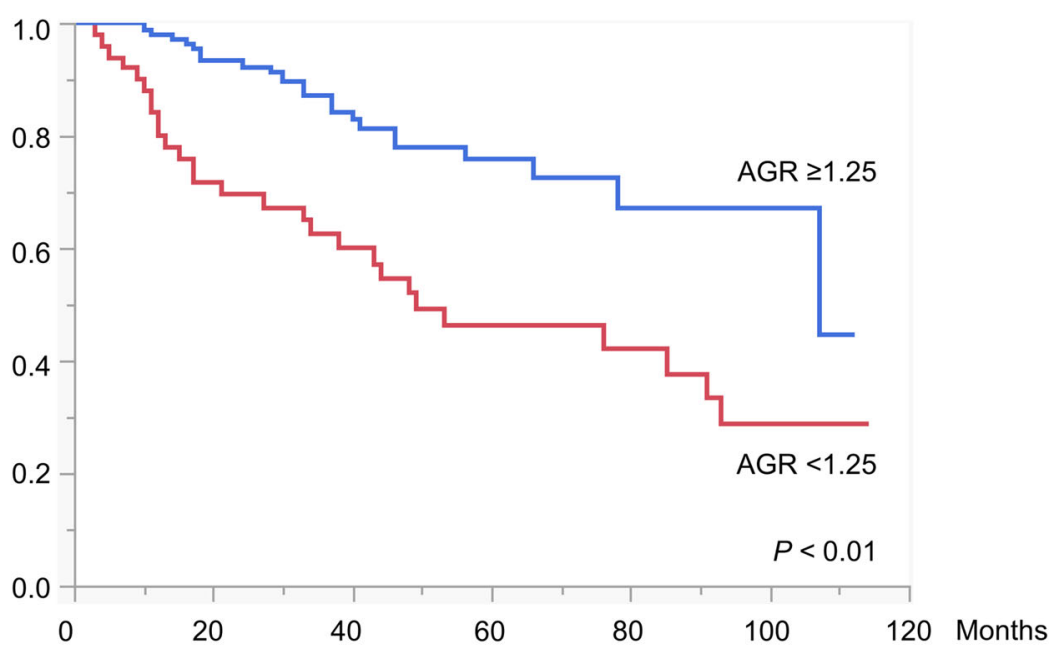

Number at risk:

$\begin{array}{lrrrrrrr}\text { AGR }<1.25 & 55 & 34 & 24 & 15 & 10 & 3 & 0 \\ \text { AGR } \geq 1.25 & 124 & 92 & 58 & 31 & 11 & 4 & 0\end{array}$

Fig. 3 Kaplan-Meier curves depicting OS a in patients with $A G R<1.25$ versus $\geq 1.25$ ( $P<0.01$, log-rank test). Abbreviations: $A G R=$ albumin-toglobulin ratio; OS = overall survival 
Table 2 Univariate and multivariate Cox proportional hazard regression analyses of CSS

\begin{tabular}{|c|c|c|c|c|c|}
\hline \multirow[t]{2}{*}{ Parameter } & \multirow[t]{2}{*}{ Cutoff } & \multicolumn{2}{|l|}{$\underline{\text { Univariate }}$} & \multicolumn{2}{|l|}{$\underline{\text { Multivariate }}$} \\
\hline & & $\mathrm{HR}(95 \% \mathrm{Cl})$ & $P$ & $\mathrm{HR}(95 \% \mathrm{Cl})$ & $P$ \\
\hline Age at surgery & Continuous & 1.03 (0.99 to 1.07) per score & 0.07 & 1.03 (0.99 to 1.08 ) per score & 0.18 \\
\hline \multirow[t]{2}{*}{ Sex } & Male & Reference & $<0.05^{*}$ & Reference & 0.14 \\
\hline & Female & 2.15 (1.09 to 4.13 ) & & 1.73 (0.83 to 3.51$)$ & \\
\hline \multirow[t]{2}{*}{ Surgical technique } & Open & Reference & 0.16 & Reference & 0.21 \\
\hline & Laparoscopic & 0.50 (0.23 to 1.34$)$ & & 2.26 (0.63 to 8.93 ) & \\
\hline \multirow[t]{2}{*}{ Tumor location } & Renal pelvis or both & Reference & 0.56 & Reference & 0.72 \\
\hline & Ureter & 1.21 (0.63 to 2.33 ) & & 1.14 (0.55 to 2.42 ) & \\
\hline \multirow[t]{2}{*}{ Tumor grade } & $\mathrm{G} 1 / 2$ & Reference & $<0.01^{*}$ & Reference & $<0.05^{*}$ \\
\hline & G3 & 4.10 (2.07 to 8.66$)$ & & 2.56 (1.07 to 6.50$)$ & \\
\hline \multirow[t]{2}{*}{ Pathological T stage } & $\leq \mathrm{T} 2$ & Reference & $<0.01^{*}$ & Reference & 0.06 \\
\hline & $\geq \mathrm{T} 3$ & 3.67 (1.88 to 7.59$)$ & & 2.51 (0.96 to 6.70$)$ & \\
\hline \multirow[t]{2}{*}{ Pathological N stage } & $\mathrm{NO} / \mathrm{x}$ & Reference & $<0.01^{*}$ & Reference & 0.20 \\
\hline & $\mathrm{N} 1-3$ & 4.82 (2.20 to 9.77$)$ & & 2.21 (0.65 to 7.00$)$ & \\
\hline \multirow[t]{2}{*}{ Adjuvant chemotherapy } & Yes & Reference & $<0.05^{*}$ & Reference & 0.51 \\
\hline & No & 0.49 (0.25 to 0.97$)$ & & 1.36 (0.55 to 3.37$)$ & \\
\hline \multirow[t]{2}{*}{ Previous or synchronous bladder cancer } & No & Reference & $<0.01^{*}$ & Reference & $<0.01^{*}$ \\
\hline & Yes & 3.61 (1.83 to 6.92$)$ & & $3.49(1.66$ to 7.19$)$ & \\
\hline \multirow[t]{2}{*}{ AGR } & $\geq 1.25$ & Reference & $<0.01^{*}$ & Reference & $<0.01^{*}$ \\
\hline & $<1.25$ & 3.90 (2.02 to 7.79$)$ & & 2.81 (1.34 to 6.10$)$ & \\
\hline
\end{tabular}

Abbreviations: $H R$ hazard ratio, $C l$ confidence interval, $A G R$ albumin-to-globulin ratio *Statistically significant

Table 3 Univariate and multivariate Cox proportional hazard regression analyses of OS

\begin{tabular}{|c|c|c|c|c|c|}
\hline \multirow[t]{2}{*}{ Parameter } & \multirow[t]{2}{*}{ Cutoff } & \multicolumn{2}{|l|}{ Univariate } & \multicolumn{2}{|l|}{ Multivariate } \\
\hline & & $\mathrm{HR}(95 \% \mathrm{Cl})$ & $P$ & $\mathrm{HR}(95 \% \mathrm{Cl})$ & $P$ \\
\hline Age at surgery & Continuous & 1.03 (1.00 to 1.07) per score & $<0.05^{*}$ & 1.03 (0.99 to 1.07) per score & 0.07 \\
\hline \multirow[t]{2}{*}{ Sex } & Male & Reference & 0.08 & Reference & 0.23 \\
\hline & Female & 1.72 (0.93 to 3.07 ) & & 1.48 (0.77 to 2.76$)$ & \\
\hline \multirow[t]{2}{*}{ Surgical technique } & Open & Reference & $<0.05^{*}$ & Reference & 0.60 \\
\hline & Laparoscopic & 0.44 (0.23 to 0.98$)$ & & 1.33 (0.47 to 4.03 ) & \\
\hline \multirow[t]{2}{*}{ Tumor location } & Renal pelvis or both & Reference & 0.92 & Reference & 0.88 \\
\hline & Ureter & 1.03 (0.58 to 1.80$)$ & & 1.05 (0.57 to 1.94$)$ & \\
\hline \multirow[t]{2}{*}{ Tumor grade } & $\mathrm{G} 1 / 2$ & Reference & $<0.01^{*}$ & Reference & $<0.05^{*}$ \\
\hline & G3 & 2.61 (1.49 to 4.67 ) & & 2.15 (1.03 to 4.52$)$ & \\
\hline \multirow[t]{2}{*}{ Pathological T stage } & $\leq \mathrm{T} 2$ & Reference & $<0.01^{*}$ & Reference & 0.27 \\
\hline & $\geq \mathrm{T} 3$ & 2.30 (1.32 to 4.08$)$ & & 1.54 (0.71 to 3.35$)$ & \\
\hline \multirow[t]{2}{*}{ Pathological N stage } & No/x & Reference & $<0.01^{*}$ & Reference & 0.09 \\
\hline & $\mathrm{N} 1-3$ & 4.32 (2.14 to 8.12$)$ & & 2.56 (0.87 to 7.09$)$ & \\
\hline \multirow[t]{2}{*}{ Adjuvant chemotherapy } & Yes & Reference & 0.33 & Reference & 0.23 \\
\hline & No & 1.36 (0.73 to 2.43 ) & & 1.62 (0.74 to 3.61$)$ & \\
\hline \multirow[t]{2}{*}{ Previous or synchronous bladder cancer } & No & Reference & $<0.01^{*}$ & Reference & $<0.05^{*}$ \\
\hline & Yes & 2.43 (1.28 to 4.39$)$ & & 1.99 (1.01 to 3.75$)$ & \\
\hline \multirow[t]{2}{*}{ AGR } & $\geq 1.25$ & Reference & $<0.01^{*}$ & Reference & $<0.05^{*}$ \\
\hline & $<1.25$ & $2.90(1.66$ to 5.15$)$ & & 2.09 (1.12 to 3.92$)$ & \\
\hline
\end{tabular}


monocyte ratio [28], have been established and wellinvestigated in the field of oncology, including urothelial carcinoma.

The major limitations of this study are its retrospective, single-institutional design and the limited number of patients. Further studies with larger populations are needed to confirm our results.

\section{Conclusions}

Given the significant prognostic associations of the AGR with CSS and OS, AGRs are easy to determine in routine clinical practice, and a preoperative AGR $<1.25$ might serve as a useful prognostic biomarker of patients with UTUC treated with radical nephroureterectomy.

\section{Supplementary information}

Supplementary information accompanies this paper at https://doi.org/10. 1186/s12894-020-00700-8.

Additional file 1: Table S1. The REporting recommendations for tumour MARKer prognostic studies (REMARK) checklist of the present study (based on the original guideline [27]).

\section{Abbreviations}

AGR: Albumin-to-globulin ratio; AUC: Area under the curve; CSS: Cancerspecific survival; IQR: Interquartile range; OS: Overall survival; ROC: Receiver operating characteristic; UTUC: Upper tract urothelial carcinoma

\section{Acknowledgements}

We thank Dr. Alla Bradley from Edanz Group (https://en-author-services. edanzgroup.com/) for editing a draft of this manuscript.

\section{Authors' contributions}

SO and ST contributed to the conception, study design, analysis, interpretation of data, and drafted the first manuscript. SM, RM, MS, NN, KM, YN, TY, MK, and MT contributed to acquisition of data. TO, EH, and HF supervised the study, helped to draft the manuscript, and were involved in revising it critically for important intellectual content. All authors read and approved the final manuscript.

\section{Funding}

None.

\section{Availability of data and materials}

Because of ethical restrictions, the raw data underlying this study are available from the corresponding author upon reasonable request.

\section{Ethics approval and consent to participate}

The present study was approved by the internal institutional review board of Kyorin University School of Medicine (approval number: 1154). This was a retrospective study, and additional informed consent was not required by the board.

\section{Consent for publication}

Not applicable.

\section{Competing interests}

The authors declare that they have no competing interests.

\section{Author details}

${ }^{1}$ Department of Urology, Kyorin University School of Medicine, 6-20-2 Shinkawa, Mitaka, Tokyo 181-8611, Japan. ²Department of ADPKD Research, Kyorin University School of Medicine, 6-20-2 Shinkawa, Mitaka, Tokyo 181-8611, Japan
Received: 15 October 2019 Accepted: 19 August 2020

Published online: 28 August 2020

\section{References}

1. Siegel RL, Miller KD, Jemal A. Cancer statistics, 2019. CA Cancer J Clin. 2019; 69:7-34.

2. Munoz J, Ellison L. Upper tract urothelial neoplasms: incidence and survival during the last 2 decades. J Urol. 2000;164:1523-5.

3. Margulis V, Shariat SF, Matin SF, Kamat AM, Zigeuner R, Kikuchi E, Lotan Y, Weizer A, Raman JD. Wood CG; upper tract Urothelial carcinoma collaboration. The upper tract Urothelial carcinoma collaboration. Outcomes of radical nephroureterectomy: a series from the upper tract Urothelial carcinoma collaboration. Cancer. 2009:115:1224-33.

4. Akaza H, Koiso K, Niijima T. Clinical evaluation of urothelial tumors of the renal pelvis and ureter based on a new classification system. Cancer. 1987. 59:1369-75.

5. Fernández MI, Shariat SF, Margulis V, Bolenz C, Montorsi F, Suardi N, Remzi M, Wood CG, Roscigno M, Kikuchi E, Oya M, Zigeuner R, Langner C, Weizer A, Lotan Y, Koppie TM, Raman JD, Karakiewicz P, Bensalah K, Schultz M, Bernier $P$. Evidence-based sex-related outcomes after radical nephroureterectomy for upper tract urothelial carcinoma: results of large multicenter study. Urology. 2009:73:142-6.

6. Kobayashi H, Kikuchi E, Tanaka N, Shirotake S, Miyazaki Y, Ide H, Obata J, Hoshino K, Matsumoto K, Kaneko G, Hagiwara M, Kosaka T, Oyama M, Nakajima Y, Oya M. Patient age was an independent predictor of cancerspecific survival in male patients with upper tract urothelial carcinoma treated by radical nephroureterectomy. Jpn J Clin Oncol. 2016;46:554-9.

7. Shibing Y, Liangren L, Qiang W, Hong L, Turun S, Junhao L, Lu Y, Zhengyong Y, Yonghao J, Guangqing F, Yunxiang L, Dehong C. Impact of tumour size on prognosis of upper urinary tract urothelial carcinoma after radical nephroureterectomy: a multi-institutional analysis of 795 cases. BJU Int. 2016;118:902-10.

8. Su X, Fang D, Li X, Xiong G, Zhang L, Hao H, Gong Y, Zhang Z, Zhou L. The influence of tumor size on oncologic outcomes for patients with upper tract Urothelial carcinoma after radical Nephroureterectomy. Biomed Res Int. 2016;2016:4368943.

9. Waseda Y, Saito K, Ishioka J, Matsuoka Y, Numao N, Fujii Y, Sakai Y, Koga F, Okuno T, Arisawa C, Kamata S, Nagahama K, Masuda H, Yonese J, Kageyama Y, Noro A, Tsujii T, Morimoto S, Gotoh S, Kihara K. Ureteral involvement is associated with poor prognosis in upper urinary tract Urothelial carcinoma patients treated by Nephroureterectomy: a multicenter database study. Eur Urol Focus. 2016;2:296-302.

10. Dabi Y, El Mrini M, Duquesnes I, Delongchamps NB, Sibony M, Zerbib M, Xylinas E. Impact of body mass index on the oncological outcomes of patients treated with radical nephroureterectomy for upper tract urothelial carcinoma. World J Urol. 2018;36:65-71.

11. Azuma T, Matayoshi $Y$, Odani $K$, Sato $Y$, Sato $Y$, Nagase $Y$, Oshi M. Preoperative neutrophil-lymphocyte ratio as an independent prognostic marker for patients with upper urinary tract urothelial carcinoma. Clin Genitourin Cancer. 2013:11:337-41.

12. Vartolomei MD, Kimura S, Ferro M, Vartolomei L, Foerster B, Abufaraj M, Shariat SF. Is neutrophil-to-lymphocytes ratio a clinical relevant preoperative biomarker in upper tract urothelial carcinoma? A meta-analysis of 4385 patients. World J Urol. 2018:36:1019-29.

13. Ku JH, Kim M, Choi WS, Kwak C, Kim HH. Preoperative serum albumin as a prognostic factor in patients with upper urinary tract urothelial carcinoma. Int Braz J Urol. 2014;40:753-62.

14. Yeh HC, Chien TM, Wu WJ, Li CC, Li WM, Ke HL, Chou YH, Wang CJ, Huang SP, Li CF, Liang PI, Huang CN. Is preoperative anemia a risk factor for upper tract urothelial carcinoma following radical nephroureterectomy? Urol Oncol. 2016;34:337.e1-9.

15. Huang J, Yuan Y, Wang Y, Chen Y, Kong W, Xue W, Chen H, Zhang J, Huang $Y$. Preoperative prognostic nutritional index is a significant predictor of survival in patients with localized upper tract urothelial carcinoma after radical nephroureterectomy. Urol Oncol. 2017:35:671.e1-9.

16. He J, Pan H, Liang W, Xiao D, Chen X, Guo M, He J. Prognostic effect of albumin-to-globulin ratio in patients with solid tumors: a systematic review and meta-analysis. J Cancer. 2017;8:4002-10.

17. Azab BN, Bhatt VR, Vonfrolio S, Bachir R, Rubinshteyn V, Alkaied H, Habeshy A, Patel J, Picon Al, Bloom SW. Value of the pretreatment albumin to 
globulin ratio in predicting long-term mortality in breast cancer patients. Am J Surg. 2013;206:764-70.

18. Shibutani M, Maeda K, Nagahara H, Ohtani H, Iseki Y, Ikeya T, Sugano K, Hirakawa $\mathrm{K}$. The pretreatment albumin to globulin ratio predicts chemotherapeutic outcomes in patients with unresectable metastatic colorectal cancer. BMC Cancer. 2015;15:347.

19. Yoshino Y, Taguchi A, Shimizuguchi T, Nakajima Y, Takao M, Kashiyama T, Furusawa A, Kino N, Yasugi T. A low albumin to globulin ratio with a high serum globulin level is a prognostic marker for poor survival in cervical cancer patients treated with radiation based therapy. Int J Gynecol Cancer. 2019:29:17-22

20. Liu J, Dai Y, Zhou F, Long Z, Li Y, Liu B, Xie D, Tang J, Tan J, Yao K, Zhang Y, Tang $Y$, He L. The prognostic role of preoperative serum albumin/globulin ratio in patients with bladder urothelial carcinoma undergoing radical cystectomy. Urol Oncol. 2016;34:484.e1-8.

21. Niwa N, Matsumoto K, Ide H, Nagata H, Oya M. Prognostic value of pretreatment albumin-to-globulin ratio in patients with non-muscle-invasive bladder Cancer. Clin Genitourin Cancer. 2018;16:e655-61.

22. Koparal MY, Polat F, Çetin S, Bulut EC, Sözen TS. Prognostic role of preoperative albumin to globulin ratio in predicting survival of clear cell renal cell carcinoma. Int Braz J Urol. 2018;44:933-46.

23. Zhang B, Yu W, Zhou LQ, He ZS, Shen C, He Q, Li J, Liu LB, Wang C, Chen $X Y$, Fan Y, Hu S, Zhang L, Han WK, Jin J. Prognostic significance of preoperative albumin-globulin ratio in patients with upper tract Urothelial carcinoma. PLoS One. 2015;10:e0144961.

24. Xu H, Tan P, Ai J, Huang Y, Lin T, Yang L, Wei Q. Prognostic impact of preoperative albumin-globulin ratio on oncologic outcomes in upper tract Urothelial carcinoma treated with radical Nephroureterectomy. Clin Genitourin Cancer. 2018;16:e1059-68.

25. Otsuka M, Kamasako T, Uemura T, Takeshita N, Shinozaki T, Kobayashi M, Komaru A, Fukasawa S. Prognostic role of the preoperative serum albumin : globulin ratio after radical nephroureterectomy for upper tract urothelial carcinoma. Int J Urol. 2018;25:871-8.

26. Fukushima H, Kobayashi M, Kawano K, Morimoto S. Prognostic value of albumin/globulin ratio in patients with upper tract Urothelial carcinoma patients treated with radical Nephroureterectomy. Anticancer Res. 2018; 38:2329-34.

27. McShane LM, Altman DG, Sauerbrei W, Taube SE, Gion M, Clark GM. Statistics Subcommittee of the NCI-EORTC Working Group on Cancer Diagnostics. REporting recommendations for tumour MARKer prognostic studies (REMARK). Eur I Cancer. 2005;41:1690-6.

28. Cantiello F, Russo GI, Vartolomei MD, ARA F, Terracciano D, Musi G, Lucarelli G, Di Stasi SM, Hurle R, Serretta V, Busetto GM, Scafuro C, Perdonà S, Borghesi M, Schiavina R, Cioffi A, De Berardinis E, Almeida GL, Bove P, Lima E, Ucciero G, Matei DV, Crisan N, Verze P, Battaglia M, Guazzoni G, Autorino R, Morgia G, Damiano R, de Cobelli O, Mirone V, Shariat SF, Ferro M. Systemic Inflammatory Markers and Oncologic Outcomes in Patients with High-risk Non-muscle-invasive Urothelial Bladder Cancer. Eur Urol Oncol. 2018;1:403-10

\section{Publisher's Note}

Springer Nature remains neutral with regard to jurisdictional claims in published maps and institutional affiliations.

Ready to submit your research? Choose BMC and benefit from:

- fast, convenient online submission

- thorough peer review by experienced researchers in your field

- rapid publication on acceptance

- support for research data, including large and complex data types

- gold Open Access which fosters wider collaboration and increased citations

- maximum visibility for your research: over $100 \mathrm{M}$ website views per year

At BMC, research is always in progress.

Learn more biomedcentral.com/submissions 